\title{
Have Business Communication Instructors Changed Their Perception Of Business Ethics? A Comparative Study With Implications For Teaching
}

\author{
Donald English, (Email: Donald_english@tamu-commerce.edu), Texas A\&M University, Commerce
} Edgar Manton, (Email: edgar_manton@tamu-commerce.edu), Texas A\&M University, Commerce Janet Walker, (Email: janet_walker@tamu-commerce.edu), Texas A\&M University, Commerce

\begin{abstract}
The purpose of this study was to determine the opinions of communication instructors in the Southeastern and Southwestern Regions of the Association for Business Communication concerning the teaching of ethics.
\end{abstract}

\section{INTRODUCTION}

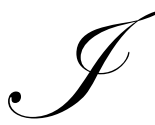
company publicly espouses may be vastly different from what is actually practiced.

Business ethics is currently one of the most important topics in business education instruction. "The Association to Advance Collegiate Schools of business" (AACSB) has studied this issue and is considering how it should be incorporated into the business curriculum. It is increasingly clear that current and future business graduates need information about acceptable business practices in order to perform effectively in ethical business environments.

\section{PROBLEM/METHODS}

The problem of this study is to determine the opinions of business communication instructors in the Southeastern and Southwestern Regions of the Association for Business Communication concerning the teaching of business ethics. A questionnaire was developed and mailed to the business communication instructors in these regions. A total of 226 questionnaires were mailed and 85 were returned for a response rate of 38 percent. Questions dealing with the value of ethics in a business curriculum, whether ethics is taught in their courses, how many class room hours are devoted to teaching ethics and how they obtained their training in ethics were some of the questions asked. In light of recent business scandals, it is hypothesized the business communication instructors are concerned about the teaching of business ethics.

\section{OBJECTIVES OF THE STUDY}

The objectives of this study are:

1. To determine if business ethics topics are included in the curriculum.

2. To determine the class hours spent on business ethics.

3. To determine the perceived value of business ethics. 
4. To determine how respondents rated undergraduate instruction in business ethics.

5. To determine if the emphasis on business ethics has changed.

6. To determine the business ethics topics taught.

7. To determine the value of various teaching methods/materials.

8. To determine how the instructors received their education in ethics.

\section{RELATED LITERATURE}

Since 2001, business educators have become familiar with Enron, Arthur Andersen, WorldCom, Tyco, and others. How has this affected instructor thinking on ethics and teaching an ethics course in colleges of business?

According to David Callahan, author of The Cheating Culture, we seem to be becoming a nation of cheaters. He says, "Executives and workers steal $\$ 600$ billion from their companies each year compared to the federal deficit total of $\$ 560$ billion". He blames the "dog eat dog economic climate of the past two decades" and pushes for cultural change (Callahan 2004).

AACSB emphasized in their revised 'Eligibility Procedures and Standards for Business Accreditation' the importance of ethics instruction. One of the standards included is Ethical understanding and reasoning abilities (AACSB, 2004).

In a speech, "Will Our Moral Compass Fail", given to the Athens West Rotary Club, Athens, Georgia in April 2003, Dr. Scherer says "the past two years (2002 and 2003) may be characterized as the most serious period of ethics scandal on the part of business since the 1980s" (Carroll and Scherer p 530). The recent scandals are far worse than previous scandals because so many employees and investors were affected. He lays the blame at the feet of top executives, auditors and accountants, government regulators, and the board of directors. Another serious concern is that few business schools offer ethics courses. Most professors seem to feel their own subject matter is more important than ethics. Since ethics is not afforded prominence in the business school, the students may also feel it is not as important (Carroll and Scherer, 2003).

Since the executives involved in the scandals attended some of the most prestigious business schools, what went wrong and what can be done for future students? Are we giving our business students provided proper training in ethics?

Certainly we can start with values education in young students. What about college students and the accountants, CEOs and lawyers that are in the workforce (Frohnen and Clarke, 2002).

Since the scandals, business schools have had to rethink their position on ethics courses. In the past, most schools have incorporated ethics in other courses. According to Clarke Thomas, there are stirrings in the business colleges indicating that ethics should be addressed more comprehensively. Perhaps there should be a separate course in ethics. There has been further support for a requirement that business colleges require ethics for AACSB accreditation.

In September 2003, Siva Sankaran, and Tung Bui report on the Relationship between Student Characteristics and Ethics: Implications for Educators.

The characteristics studied are competitiveness, personality type, age, gender, and major. A sample of 345 college students was studied. Results showed that ethics is inversely related to competitiveness, ethics improves with age, gender does not impact ethics, and level of ethics differs across majors. Teaching strategies to improve ethics are presented (p.245).

Sankaran and Bui recommend ethics be a part of every curriculum. Teaching activities should include case studies, role-playing, debates, and internship experience focusing on feeling of those who receive unethical treatment. Educational institutions must enforce a strong code of ethics; instructors should strictly enforce ethics in the 
classroom. Students should be able to anonymously access the instructor to report unethical practices, and ethical issues related to their discipline should be discussed in class.

Other instructional techniques include the following: the University of Maryland is taking MBA students to a federal prison to talk with executives turned inmate about the consequences of compromising ethical standards. (Carroll et al., 2003) Many business schools have a new ethics course. Harvard requires all new MBA students to take an interdisciplinary ethics course that includes case studies of Enron and WorldCom. Undergraduate business students in Arizona have to sign an "integrity oath" and faculty members use plagiarism-detecting software (Mangan, 2004). In his speech, "Improper Corporate Behavior" Ronald Berenbeim discusses his business ethics course at the Stem School of Business Administration, New York University. He reports on "Enron's Syllabus of Errors because the company is a perfect pedagogical instrument for teaching an entire course in business ethics (p 306).

Students at the University of Arizona analyze case studies and are asked to make ethical decisions on the spot. At Saint Vincent College in Pennsylvania, a capstone course, Ethical Environment in the Accounting profession will help students better understand the choices accountants have to make today (Nicole, 2002).

The University of St. Thomas's College of Business reported that Enron has become "a teaching moment." Efforts are made to bring ethics into all the professional courses. All students take an introductory course in ethics and end their studies with a capstone that relates ethical responsibility to their individual field of study (Lefevere, 2002). Business school professors need to think about how their classes help prepare students for the business world and the ethical decisions they will have to make.

\section{METHODOLOGY}

In the 1999 survey 250 questionnaires were sent to the members of the Southwestern and Southeastern regions of the Association of Business Communication. Of these 65 were returned at a response rate of $26 \%$.Fifty four or $21.6 \%$ percent were usable. For the 2004 survey questionnaires were again sent to all members of both organizations. A total of 226 questionnaires were sent and 85 were returned for a response rate of $38 \%$. Seventy two or $32 \%$ returned were usable. The same questions were asked in both surveys - questions dealing with the value of ethics to a business curriculum, whether ethics is taught in their courses, how many class room hours are devoted to teaching ethics and how they obtained their training in ethics. In addition the instructors were asked in the 2004 survey whether they had increased the emphasis on the ethics in their courses and if so, for what reason(s).

\section{FINDINGS}

In 1999,45 or $83 \%$ of the respondents indicated that they taught business ethics in their communication classes. By 2004 the percent teaching ethics in the class grew to $92 \%$ - 66 of the 72 respondents (See Table 1).

Table 1

Do you teach business ethics topics in your course(s)?

\begin{tabular}{|l|c|c|c|c|}
\hline \multirow{2}{*}{ Response } & \multicolumn{2}{|c|}{$\mathbf{1 9 9 9}$} & $\mathbf{2 0 0 4}$ & $\mathbf{2}$ \\
\cline { 2 - 5 } & $\mathbf{N}$ & $\mathbf{\%}$ & 66 & 92 \\
\hline Yes & 45 & 83 & 6 & 8 \\
\hline No & 9 & 17 & 72 & 100 \\
\hline Total & 54 & 100 & 2 & \\
\hline
\end{tabular}

In 2004 only 6 of the instructors indicated that they were not teaching ethics compared to 9 in 1999.In 1999, half of those not teaching ethics presently in their course was because the curriculum contents of their courses were too full - eight out of nine in 1999 and three out of six in 2004 (see Table 2). None of the 6 instructors who do not currently teach ethics plan to introduce ethics topics into their courses in the near future (see Table 3 ). 
Table 2

If "No", why is business ethics not included in the business curriculum?

\begin{tabular}{|l|c|c|c|c|}
\multirow{2}{*}{ Response } & \multicolumn{2}{|c|}{$\mathbf{1 9 9 9}$} & \multicolumn{2}{|c|}{$\mathbf{2 0 0 4}$} \\
\cline { 2 - 5 } & $\mathbf{N}$ & $\mathbf{\%}$ & $\mathbf{N}$ & $\mathbf{\%}$ \\
\hline Curriculum too full & 8 & 89 & 3 & 1 \\
\hline Not an appropriate topic for my course & 2 & 22 & 1 & 17 \\
\hline Inadequate instructional material available & 2 & 22 & 0 & 0 \\
\hline Ethics cannot be taught in classroom setting & 0 & 0 & 0 & 0 \\
\hline Lack of personal Interest & 1 & 11 & 0 & 0 \\
\hline Subject Inappropriate for Business School & 0 & 0 & 33 & 17 \\
\hline Other & 3 & 33 & 1 & 0 \\
\hline
\end{tabular}

Table 3

Do you anticipate incorporating business ethics into your courses(s) in the near future?

\begin{tabular}{|l|c|c|c|c|}
\hline \multirow{2}{*}{ Response } & \multicolumn{2}{|c|}{$\mathbf{1 9 9 9}$} & \multicolumn{2}{|c|}{$\mathbf{2 0 0 4}$} \\
\cline { 2 - 5 } & $\mathrm{N}$ & $\%$ & $\mathrm{~N}$ & 0 \\
\hline Yes & 2 & 11 & 4 & 0 \\
\hline No & 4 & 45 & 2 & 67 \\
\hline Undecided & 3 & 33 & 2 & 33 \\
\hline Total & 9 & 99 & 6 & 100 \\
\hline
\end{tabular}

In both the 1999 and the 2004 surveys the respondents who teach ethics in their courses were asked to indicate how valuable ethics instruction is in the business curriculum. The vast majority of the instructors rated ethics instruction in the business program as either "very valuable" or "valuable" in both studies. In the 1999 survey, $56 \%$ of the respondents indicated that such instruction is "very valuable" to the business curriculum compared to 2004 where the percent of respondents indicating that ethics instruction is "very valuable" had increased to 70\% (see Table 4).

Table 4

How valuable is business ethics instruction?

\begin{tabular}{|l|c|c|c|c|}
\hline \multirow{2}{*}{ Response } & \multicolumn{2}{|c|}{$\mathbf{1 9 9 9}$} & \multicolumn{2}{|c|}{$\mathbf{2 0 0 4}$} \\
\cline { 2 - 5 } & $\mathbf{N}$ & $\mathbf{\%}$ & $\mathbf{N}$ & $\mathbf{\%}$ \\
\hline Very Valuable & 25 & 56 & 46 & 70 \\
\hline Valuable & 20 & 44 & 16 & 24 \\
\hline Little Value & 0 & 0 & 2 & 3 \\
\hline No Value & 0 & 0 & 0 & 0 \\
\hline Undecided & 0 & 0 & 2 & 3 \\
\hline Total & 45 & 100 & 66 & 100 \\
\hline
\end{tabular}

The instructors who teach ethics were asked how many hours they spend covering on ethical topics in their courses. Fifty -seven percent of the current instructors indicated that they spend three or more hours on the study of ethical topics compared to 51\% who indicated that they spent this amount of time in 1999. Fifteen percent of the 1999 respondents stated that they spend 5 or more hours on discussing ethical issues compared to 24 percent in the 2004 survey (see Table 5).

Table 5

How many class hours are spent per semester on business ethics?

\begin{tabular}{|l|c|c|c|c|}
\hline \multirow{2}{*}{ Response } & \multicolumn{2}{|c|}{$\mathbf{1 9 9 9}$} & $\mathbf{2 0 0 4}$ \\
\cline { 2 - 5 } & $\mathbf{N}$ & $\mathbf{\%}$ & $\mathbf{N}$ & $\mathbf{\%}$ \\
\hline Less than One hour & 3 & 7 & 3 & 5 \\
\hline One hour to less than Three hours & 19 & 42 & 25 & 38 \\
\hline Three hours to less than Four hours & 16 & 36 & 22 & 33 \\
\hline Five hours to less than Seven hours & 5 & 11 & 9 & 14 \\
\hline Seven hours or more & 2 & 4 & 7 & 10 \\
\hline Total & 45 & 100 & 66 & 100 \\
\hline
\end{tabular}


The 2004 respondents were asked whether they had increased their emphasis on ethics instructions during the past four years. Seventy-four percent of the respondents answered "yes" (see Table 6). If they responded "yes" to the question of increasing their efforts in ethics they were then asked "why". The vast majority - 71\% - indicated that it was due to the recent business scandals. Other causes identified by about one fourth of the respondents were 1) pressure from the AACSB, 2) from college advisory council recommendations and 3) from internal faculty curriculum reviews (see Table 7).

Table 6

Have you increased the emphasis on business ethics in your course(s) in the last four years?

\begin{tabular}{|l|c|c|}
\hline Response & Number & Percent \\
\hline Yes & 49 & 74 \\
\hline No & 15 & 23 \\
\hline Undecided & 2 & 3 \\
\hline Total & 66 & 100 \\
\hline
\end{tabular}

Table 7

If "yes", why did you increase the emphasis on teaching business ethics?

\begin{tabular}{|l|c|c|}
\hline \multirow{2}{*}{ Response } & $\mathbf{N}$ & $\mathbf{2 0 0 4}$ \\
\cline { 2 - 3 } & 35 & 71 \\
\hline Because of Business Scandals & 14 & 28 \\
\hline Because of AACSB accreditation & 12 & 24 \\
\hline Advisory council recommendations & 11 & 22 \\
\hline Curriculum Reviews & 8 & 16 \\
\hline Demand by corporations that ethics be taught & 10 & 20 \\
\hline Other & & . \\
\hline
\end{tabular}

The instructors were queried as to which ethics topics they felt were important to be included in their courses. Twenty six topics were selected based on a review of the literature and previous studies. These topics and the numbers and percentages of respondents selecting them for both surveys are included in Table 8 . The first eight topics chosen in 1999 are same as those chosen by the current respondents with only a slight reordering of their ranks. The most selected topic in both surveys, "ethical communication", increased in percentage of respondents selecting it - with 84\% choosing this topic in 1999 compared to $92 \%$ in 2004. "Ethics and Culture" was the second highest topic chosen in both surveys receiving $73 \%$ in each study.

The "definition of ethics, morals and laws was rated $4^{\text {th }}$ in the 1999 survey, but rose to third in the latest study, increasing from $64 \%$ to $72 \%$ of the respondents selecting it. Five of the remaining six highest selected topics had about the same percentage of respondents choosing them in both surveys - these were "individual values", "attitude towards ethics", "monitoring employee voicemail", "e-mail and telephone usage", and "violation of copyright". "Sexual Harassment" moved from $5^{\text {th }}$ to $7^{\text {th }}$ place with the percentage dropping from $58 \%$ to $53 \%$.

There were five factors which increased significantly in percentage of respondents and in rank from the 1999 to the 2004 study. "Reporting ethical violations" rose from $19^{\text {th }}$ in rank to $9^{\text {th }}$ with $31 \%$ of the respondents selecting it in 1999 compared to $45 \%$ in 2004. "Ethics in foreign markets" went from $15^{\text {th }}$ place to $10^{\text {th }}$ place with $38 \%$ selecting this topic in 1999 compared with $44 \%$ in 2004. "Truth in advertising" increased from 36\% to $39 \%$ moving it from $17^{\text {th }}$ to the $12^{\text {th }}$ ranked topic. Other topics experiencing an increase in respondents percentage of selections were "dealing with and concern for community" went from $22 \%$ to $31 \%$ of the respondents selecting it and from $22^{\text {nd }}$ ranked topic to $17^{\text {th }}$ (tie) and "understanding conflict of interest" going from $20 \%$ to $31 \%$ moving up in rank from $23^{\text {rd }}$ to the $17^{\text {th }}$ (tie).

There were five factors which had a reduction of more than five percentage points in respondent selections between the two surveys. These factors seemed to deal with the workplace environment and with products. Instruction 
about "bosses requesting compromise in ethical behavior" went from $47 \%$ in 1999 to $36 \%$ in 2004 and dropped from the $9^{\text {th }}$ to the $14^{\text {th }}$ ranked topic. "Misrepresentation of product features" and "software piracy" both declined from 40 to $34 \%$ dropping from $13^{\text {th }}$ to $15^{\text {th }}$ (tied) in rank. "Legal and regulatory issues" dropped in rank from $15^{\text {th }}$ to $17^{\text {th }}$ (tie) with $31 \%$ in 2004 vs. $38 \%$ in 1999 . Dropping from $43 \%$ in 1999 to $28 \%$ in 2004 and from $11^{\text {th }}$ position to $21^{\text {st }}$ was "issues dealing with data privacy", while "health and safety concerns" dropped from $29 \%$ to $22 \%$ falling from $20^{\text {th }}$ to $24^{\text {th }}$ rank on the list (See Table 8).

Table 8

Important Business Ethics Topics

\begin{tabular}{|c|c|c|c|c|c|c|c|}
\hline \multirow{2}{*}{\multicolumn{2}{|c|}{ Topic }} & \multicolumn{3}{|c|}{1999} & \multicolumn{3}{|c|}{2004} \\
\hline & & $\mathbf{N}$ & $\%$ & Rank & $\mathbf{N}$ & $\%$ & Rank \\
\hline 1 & Ethical Communication & 38 & 84 & $(1)$ & 59 & 92 & $(1)$ \\
\hline 2 & Ethics and Culture & 33 & 73 & $(2)$ & 47 & 73 & $(2)$ \\
\hline 3 & Definition of Ethics, Morals and Law & 29 & 64 & (4) & 46 & 72 & (3) \\
\hline 4 & Individual Values & 30 & 67 & (3) & 42 & 66 & (4) \\
\hline 5 & Attitude towards Ethics & 25 & 56 & $(7)$ & 37 & 58 & $(5)$ \\
\hline 6 & Monitoring Employee Voice Mail, Email and Telephone Usage & 26 & 58 & (5) & 35 & 55 & (6) \\
\hline 7 & Sexual Harassment & 26 & 58 & $(5)$ & 34 & 53 & $(7)$ \\
\hline 8 & Violation of Copyright & 22 & 49 & $(8)$ & 31 & 48 & $(8)$ \\
\hline 9 & Reporting Ethical Violations & 14 & 31 & (19) & 29 & 45 & $(9)$ \\
\hline 10 & Ethics in foreign Markets & 17 & 38 & $(15)$ & 28 & 44 & $(10)$ \\
\hline 11 & Taking Credit for Work Not Done & 21 & 47 & (9) & 27 & 42 & $(11)$ \\
\hline 12 & Truth in Advertising & 16 & 36 & (17) & 25 & 39 & (12) \\
\hline 13 & Bribery & 19 & 42 & (12) & 24 & 38 & (13) \\
\hline 14 & Boss requests compromise of ethics & 21 & 47 & (9) & 23 & 36 & (14) \\
\hline 15 & Misrepresentation of Product Features and attributes & 18 & 40 & (13) & 22 & 34 & $(15)$ \\
\hline 16 & Software Piracy & 18 & 40 & $(13)$ & 22 & 34 & $(15)$ \\
\hline 17 & Affirmative action & 15 & 33 & $(18)$ & 20 & 31 & $(17)$ \\
\hline 18 & Dealing with and concern for the community & 10 & 22 & (22) & 20 & 31 & (17) \\
\hline 19 & Legal / Regulatory & 17 & 38 & $(15)$ & 20 & 31 & $(17)$ \\
\hline 20 & Understanding conflict of Interest & 9 & 20 & (23) & 20 & 31 & (17) \\
\hline 21 & Data Privacy & 34 & 43 & (11) & 18 & 28 & (21) \\
\hline 22 & Environmental Pollution & 11 & 24 & $(21)$ & 17 & 27 & $(22)$ \\
\hline 23 & Appreciate Business Entertainment Expense & 9 & 20 & $(23)$ & 14 & 22 & $(23)$ \\
\hline 24 & Health and Safety Concerns of the workplace & 13 & 29 & $(20)$ & 14 & 22 & (24) \\
\hline 25 & Accurate Expense Reporting & 8 & 18 & (26) & 12 & 19 & $(25)$ \\
\hline 26 & Reporting time correctly & 9 & 20 & $(23)$ & 12 & 19 & (26) \\
\hline
\end{tabular}

Table 9 presents data concerning the use of fourteen methods and materials used to present and teach ethics topics. Respondents were requested to indicate that the method or material was "very valuable", "valuable", "of little value" or of "no value". These responses were scored 4, 3, 2 and 1 respectively.

"Class discussions" dropped from first place in 1999 to $2^{\text {nd }}$ in 2004 dropping from a mean of 3.91 to 3.52 . "Case studies" took over first place in 2004 moving up from $2^{\text {nd }}$ in 1999 improving its average score to 3.54 from 3.40. "Current events" remained in place \#3, but increased in score from 3.28 to 3.45. Group projects, business simulations and student presentations remained in the top positions, but all increased their mean scores significantly.. "Lectures" slipped from $6^{\text {th }}$ to $11^{\text {th }}$ with almost equal scores of 2.73 and 2.75 for the two periods.

The lowest factors from the 1999 survey - role playing, debates and panel discussion - all moved significantly higher in the 2004 survey scores. Audio visual materials, term papers and text book reading all dropped in position on the list but retained approximately the same mean scores between the two periods investigated. 
Table 9

Value Of Various Methods/Materials

Very Valuable $=4$, Valuable $=3$, Little Value $=2$, No Value $=1($ Weighted Average $)$

\begin{tabular}{|l|l|c|c|c|c|}
\hline \multirow{2}{*}{ Topic } & \multicolumn{2}{|c|}{$\mathbf{1 9 9 9}$} & \multicolumn{3}{c|}{$\mathbf{2 0 0 4}$} \\
\cline { 2 - 6 } & W & Rank & W & Rank \\
\hline 1 & Case Studies & 3.40 & 2 & 3.54 & 1 \\
\hline 2 & Discussion & 3.91 & 1 & 3.52 & 2 \\
\hline 3 & Current Events & 3.28 & 3 & 3.45 & 3 \\
\hline 4 & Guest Speaker & 2.75 & 5 & 3.42 & 4 \\
\hline 5 & Group Project & 2.53 & 7 & 3.26 & 5 \\
\hline 6 & Business Simulations & 2.22 & 10 & 3.19 & 6 \\
\hline 7 & Student Presentations & 2.48 & 8 & 3.18 & 7 \\
\hline 8 & Role Playing & 2.15 & 12 & 3.07 & 8 \\
\hline 9 & Debates & 1.85 & 13 & 2.98 & 9 \\
\hline 10 & Panel Discussion & 1.77 & 14 & 2.89 & 10 \\
\hline 11 & Audio/Visual Materials & 2.20 & 11 & 2.89 & 11 \\
\hline 11 & Lectures & 2.73 & 6 & 2.75 & 11 \\
\hline 13 & Student Term Papers & 2.48 & 8 & 2.59 & 13 \\
\hline 14 & Text Book Reading & 2.95 & 4 & 2.89 & 14 \\
\hline
\end{tabular}

The instructors were asked to evaluate their school's undergraduate instruction in ethics. Sixty - three percent of the 2004 respondents evaluated their school's instruction in ethics as "excellent", "very good" or "good" compared to $51 \%$ of the 1999 respondents. In $1999,11 \%$ of the instructors evaluated their program as excellent compared to only 1 percent of the 2004 respondents. However the "very good category" went from $9 \%$ in 1999 to $24 \%$ in 2004 and the "good" category grew to $38 \%$ from $33 \%$ (see Table 10 ).

Table 10

How would you rate your college's/school's undergraduate instruction in business ethics?

\begin{tabular}{|l|c|c|c|c|}
\hline \multirow{2}{*}{ Response } & \multicolumn{3}{|c|}{$\mathbf{2 0 9 9}$} & \multicolumn{3}{|c|}{$\mathbf{2 0 0 4}$} \\
\cline { 2 - 6 } & $\mathbf{N}$ & $\mathbf{\%}$ & $\mathbf{N}$ & $\mathbf{\%}$ \\
\hline Outstanding & 5 & 11 & 1 & 1 \\
\hline Very Good & 4 & 9 & 16 & 24 \\
\hline Good & 15 & 33 & 25 & 38 \\
\hline Fair & 10 & 22 & 12 & 18 \\
\hline Poor & 5 & 11 & 5 & 8 \\
\hline
\end{tabular}

Of interest to the researchers was, how the instructors received their educational training to enable them to teach ethics? As in the previous study where $87 \%$ of the respondents indicated that they learned on their own, in the 2004 study $85 \%$ indicated they prepared themselves to teach ethics. Only 30 percent of the current instructors reported having faculty development opportunities compared to $42 \%$ in the 1999 study. In both surveys a minority of respondents indicated that they had had specific training within their educational programs - 7\% in 1999 and $10 \%$ in 2004 (see Table 11).

Table 11

How did you receive preparation to teach business ethics?

\begin{tabular}{|l|c|c|c|c|}
\hline \multirow{2}{*}{ Response } & \multicolumn{2}{|c|}{$\mathbf{1 9 9 9}$} & \multicolumn{3}{|c|}{$\mathbf{2 0 0 4}$} \\
\cline { 2 - 6 } & $\mathbf{N}$ & $\mathbf{\%}$ & $\mathbf{N}$ & $\mathbf{\%}$ \\
\hline Self Taught & 39 & 87 & 56 & 85 \\
\hline Faculty Development Opportunities & 19 & 42 & 16 & 30 \\
\hline Program Curriculum for my degree & 7 & 16 & 7 & 10 \\
\hline Specific Courses taken & 3 & 7 & 7 & 10 \\
\hline Other & 8 & 18 & 10 & 15 \\
\hline
\end{tabular}




\section{SUMMARY AND CONCLUSIONS}

A survey was conducted of the business communication instructors who are members of the Southeastern and the Southwestern Regions of the Association for Business Communications to determine their views teaching of business ethics. Seventy percent of the respondents in the current survey stated that ethics instruction in the business curriculum is "very important." The most important ethical issues were ethical communication, ethics and culture, definition of ethics and individual values. Those factors which received lower responses from the first survey seem to deal with the corporation and its products and use of corporate resources. These were: boss' request for a compromise on ethics, misrepresentation of product features, software piracy, data privacy and dealing with concern for the community.

In valuing methods and materials to use in teaching ethics respondents indicated the importance of case studies, discussion groups, analysis of current events and the use of guest speakers in supporting the teaching of ethical issues. All of these seem to emphasize group efforts and ways to openly present, discuss and debate views on the ethical issues. Almost all (92\%) of the instructors report teaching ethics in their classes. The majority reported spending three or more class hours in a semester discussing ethics. More than $80 \%$ of the respondents report that they were self taught in the instruction of ethics in their courses. The majority of the respondents felt that their undergraduate instruction in ethics was "good", "very good", or "outstanding". Over $70 \%$ of those surveyed indicated that there had been an increased emphasis on ethics during the previous four years. Seventy percent of these respondents indicated that the increase in emphasis was due to the recent business scandals. About one fourth of the respondents reported that the AACSB had a role in the increased emphasis. Also cited for the increased emphasis were recommendations from business advisory councils and the result of internal faculty curriculum reviews.

From the findings of this study it is clear that the recent business scandals have had an impact upon the teaching of ethics by communications instructors in the schools of business included in the survey. More emphasis has been placed upon the teaching of ethics in the past four years. More time is allotted to teaching this subject in the business curriculum. Of concern is the way that teachers have had to train themselves in the teaching of ethics in their courses. More than $80 \%$ of those surveyed indicated that they trained themselves to handle this very important topic. Colleges of business must seek ways and means to provide proper training and development for faculty who will be assigned to teach ethics in the business curriculum in the future.

\section{REFERENCES}

1. AASCB International. (2004, January). Eligibility Procedures and Standards for Business Accreditation [Brochure]. (pp. 71).

2. Berenbeim, Ronald. (2002). Improper corporate behavior. [Electronic version]. Vital Speeches of the Day, 68, 305-308.

3. Callahan, David (2004). The Cheating Culture: Why more Americans are doing wrong to get ahead. Orlando, Florida: Harcourt Books.

4. Carroll, Archie B. \& Scherer, Robert W. (2003). Business Ethics In The Current Environment Of Fraud And Corruption. [Electronic version]. Vital Speeches of the Day, 69, 529-533.

5. Frohnen, Bruce \& Clarke, Leo. (2002, November). Scandal in Corporate America: An Ethical, Not a Legal Problem. USA Today. 131, 24-26.

6. Lefevere, Patricia. (2002, October 25). Corporate scandal as a teaching moment. National Catholic reporter. 39,37 .

7. Mangan, Katherine S., (2004). Business schools and company CEO's to create ethics center. Chronicle of Higher Education. 50, A9. Retrieved March 31, 2004, from Academic Search Premier database.

8. $\quad$ Nicole, Rivard. (2002, October). Emphasis on ethics. University Business. 8,17.

9. Sankaran, Siva \& Bui, Tung. (2003, September). Relationship between student characteristics and ethics: Implications for educators. Journal of Instructional Psychology. 30, 240-253.

10. Thomas, Clarke.(2002, December 4). Ethics are good business. Post-gazette.com. Retrieved from http://www.post-gazette.com/forum/comm/20021204edclar04p1.asp 